Int. J. Electrochem. Sci., 15 (2020) $7585-7600$

International Journal of

ELECTROCHEMICAL

SCIENCE

$\underline{\text { WWW.electrochemsci.org }}$

\title{
Regulation Polysulfide Conversion by Flexible Carbon Cloth/Molybdenum Selenide to Improve Sulfur Redox Kinetics in Lithium-Sulfur Battery
}

\author{
Hua Yang ${ }^{1}$, Mingshan Wang ${ }^{1, *}$, Tao Wang ${ }^{1}$, Hao Xu ${ }^{1}$, Zhenliang Yang ${ }^{2}$, Lei Zhang ${ }^{2}$, \\ Junchen Chen ${ }^{l}$, Yun Huang ${ }^{1}$, Xing Li ${ }^{l, *}$ \\ ${ }^{1}$ School of New Energy and Materials, Southwest Petroleum University, Chengdu, Sichuan 610500, \\ P.R. China \\ ${ }^{2}$ Institute of Materials, China Academy of Engineering Physics, Mianyang, Sichuan 621907, P.R. \\ China \\ *E-mail: ustbwangmingshan@163.com (M. Wang); lixing198141@163.com (X. Li)
}

doi: $10.20964 / 2020.08 .72$

Received: 5 April 2020 / Accepted: 30 May 2020 / Published: 10 July 2020

Lithium-sulfur (Li-S) batteries have been regarded as a competitive candidate for next generation electrochemical energy-storage technologies. However, the insulation of charge and discharge products (sulfur and lithium sulfide) and the shuttle efforts of lithium polysulfides (LiPSs), result in not only a series of phase conversion but also sluggish redox kinetics in Li-S electrochemistry. Herein, we firstly designed a flexible carbon cloth/molybdenum selenide $\left(\mathrm{CC} / \mathrm{MoSe}_{2}\right)$ by growing ultra-thin $\mathrm{MoSe}_{2}$ nanosheets on CC as binder-free electrode to understand the regulation mechanism in Li-S battery. With systematic electrochemical investigation of in-situ deposition $\mathrm{Li}_{2} \mathrm{~S}_{8}$ in $\mathrm{CC} / \mathrm{MoSe}_{2}$, it is found that $\mathrm{CC} / \mathrm{MoSe}_{2}$ exhibits high LiPSs chemical adsorption and electrocatalytic activity, which large enhances the LiPSs conversion. The dynamic regulation of LiPSs change the nucleation and growth of $\mathrm{Li}_{2} \mathrm{~S}$, resulting in high uniform distribution on $\mathrm{CC} / \mathrm{MoSe}_{2}$ electrode. Thus, it obtains high sulfur redox kinetics and utilization, which achieves initial capacity of $1142 \mathrm{mAh} \mathrm{g}^{-1}$ with low capacity fade of only $0.038 \%$ per cycle over 500 cycles at $1 \mathrm{C}$. Even at high $\mathrm{S}$ loading $\left(4 \mathrm{mg} \mathrm{cm}^{-2}\right)$ and extremely low electrolyte/S (E/S) ratio of $6.2 \mu \mathrm{L} \mathrm{mg}^{-1}$, it still delivers $1204 \mathrm{mAh} \mathrm{g}^{-1}$ after 100 cycles at $0.2 \mathrm{C}$ with $93.3 \%$ capacity maintain.

Keywords: Molybdenum selenide; Binder-free electrode; Lithium sulfide; Lean electrolyte; Lithiumsulfur battery

FULL TEXT 
(C) 2020 The Authors. Published by ESG (www.electrochemsci.org). This article is an open access article distributed under the terms and conditions of the Creative Commons Attribution license (http://creativecommons.org/licenses/by/4.0/). 